\title{
The Information Content of Directors' Trades: Empirical analysis of the Australian Market
}

Harminder Singh ${ }^{\bullet}$ and Lisa Hotson ${ }^{\star}$

- Corresponding Author: Lecturer, (PhD, M.Com) School of Accounting Economics and Finance, Deakin University, Australia. Phone No: 61-3-92446233. Email: singh@deakin.edu.au.

- School of Accounting Economics and Finance, Deakin University, Australia, Email: lhot@deakin.edu.au 


\title{
The Information Content of Directors' Trades: Empirical analysis of the Australian Market
}

\begin{abstract}
We examine the trading activities of directors in shares of their own companies on the Australian Stock Exchange during the July-December 2005 period. We find that directors of small companies in particular earn abnormal return after both their 'Purchase' and as well as their 'Sale' trade. Directors of these companies have an uncanny ability to time the market by trading when mispricing is greatest, and are able to predict the future performance of their firms in short run. For directors of medium and large companies, we find evidence that 'Sale' trades are the ones which generate some abnormal return. Outsiders recognise to some extent that directors' trades are informative, however they are slow to incorporate the new information into prices, refuting much of the market efficiency literature.
\end{abstract}




\section{The Information Content of Directors' Trades: Empirical analysis of the Australian Market}

\section{Introduction:}

The most radical line of reasoning objects to any form of trading that is on the basis of differentials in information. This information asymmetry in favour of directors and other company personnel may provide incentives for trading due to their exclusive positions. Possible abnormal profits may be made, at the expense of other less informed investors. As a result, actions by corporate insiders are deemed to have information signalling properties; perhaps none more so than a director's own trading activities.

Insider trading has been regulated in Australia under various Securities Industry Acts since 1970 and is an offence in the majority of the world's capital markets. Whilst insider trading typically has a negative connotation associated with it, this study does not attempt to give credence to whether insider trading is harmful, nor whether it should or should not be regulated. Rather, the purpose is much simpler. We examine whether insider trading is prevalent in the market, given the current regulatory structure in which it is prohibited. Thus, there are important public policy implications. It may indicate whether directors appear to blatantly disregard the law and whether the current regulatory structure is effective.

Numerous studies in the United States have examined corporate insider trading, primarily because of the availability of data there. Despite the extensive data pertaining to the U.S, a number of questions remain unresolved. Additionally, insider trading literature in regards to Australia is scarce because of its slow adoption of disclosure requirements and thus there is an apparent lack of data needed to conduct research. Although data are now available the literature is only just starting to gain momentum. This provides the basis for our research, especially considering that directors are likely to be in possession of the most inside information.

We attempt to contribute to the remaining unresolved issues and to the lack of empirical research pertaining to Australia. We use directors' trading as a proxy for corporate insider information. Directors as corporate insiders have an intimate knowledge of the workings of a firm and have timely access to financial performance figures. 
Considering this as a back drop their predictability of the company's performance and the stock market response appears to be better at least in short term. We propose, along with John and Lang (1991), that a corporate insider's asymmetric knowledge advantage comes from a combination of factors, including the aforementioned: (a) intimate access to information about firm operations; (b) superior analytical and/or predictive ability; and additionally (c) knowledge about specific accrual quality.

We extend on Brown and Foo's (1997) research by examining the share price performance of companies surrounding registered directors' trades. If directors trade on the basis of information, which they and only they have and earn abnormal return in a relatively short span it is likely that their trades contain information regarding the future performance of the company. Thus, investors have a strong incentive to attempt to mimic the trading patterns of directors or refrain from trading based on the potential information that their trades may contain, and potential gains to be made.

With this in mind, the primary aim of this study is to answer the following questions:

1. Do directors earn abnormal returns from trades in their own companies?

2. Can investors mimic directors' trades and earn abnormal returns?

Importantly, our research is not only a test of insider trading, but also of market efficiency. Evidence of the ability to earn superior returns based on recorded corporate insider trades has implications for the efficiency of securities markets. A market is efficient depending on the information set which is incorporated into prices. If directors are able to earn abnormal returns on the basis of private information, or if outsiders are able to earn abnormal returns from portfolios constructed on the basis of the trading behaviour of directors, this would indicate the existence of an inefficient market. Results from previous studies overseas indicate that the market is not strong form efficient i.e. prices do not contain private information; however the studies do not provide consistent evidence as to whether the market is semi-strong form efficient. Thus, it is appropriate to determine the state of efficiency in regards to the Australian market, which is nevertheless a by-product of examining insider trading. 
When insiders are optimistic, markets do well, and when insiders are pessimistic, markets do poorly, with an annual spread in returns between the two states exceeding 10\%. (Lakonishok and Lee, 2001). Section 205G (4) of the Corporations Act 2001 requires directors to notify the ASX within 14 days after any change in the director's interests. Section 3.19A.2 of the ASX Listing Rules requires that any change to the notifiable interest of directors must be given to the ASX, using Appendix 3Y, no more than five business days after the change occurs. However, recently reported (eg Gettler 2005) commercial research finds notification breaches by 62\% of the largest 200 listed companies (BT Advisory Group 2005), plus transgressions of corporate charters.

If directors' trades do contain information, then according to the semi-strong form of market efficiency, when the trade becomes public knowledge, this should be reflected in the share price. Outsiders should not be able to make abnormal profits from trading on this information. Seyhun (1986), and Rozeff and Zaman (1988) found results consistent with the semi-strong form of market efficiency. Net of transaction costs, outsiders do not benefit from imitating investors. More recently, however, and using a sample of trades with a relatively shorter delay between trade and disclosure, Bettis, Vickrey and Vickrey (1997) found that both insiders and outsiders can earn abnormal profits, net of transaction costs in the short and long-term. This study has important market efficiency implications. If, as suggested, investors are able to earn abnormal profits from publicly available information, the market is not semi-strong form efficient.

\section{Literature Review}

A number of studies have observed abnormal stock price movements immediately prior to the public announcement of a major event. ${ }^{1}$ This is consistent with the use of specific private information, such as purchasing before the public release of good news and selling before the release of bad news. This evidence indicates that a few market players have prior knowledge of forthcoming events and that information is partially impounded into the price of a security before the information is officially publicly released. Keown and Pinkerton (1981) provide evidence of excess returns

\footnotetext{
${ }^{1}$ Information asymmetry is likely to be higher in pre-announcement periods.
} 
earned prior to the first public disclosure of merger announcements. They cite that systematic abnormal returns can be interpreted as prima facie evidence of the market's reaction to information in advance of its public announcement. In essence, they contend that impending mergers are poorly held secrets and that trading on nonpublic information is extensive. Similar findings have been observed in the lead up to dividend announcements (John and Lang, 1991), mergers [(Keown and Pinkerton, 1981), (Agarwal and Singh, 2006)], share repurchases (Lee, Mikkelson et al., 1992), earnings announcements (Park, Jang et al., 1995), and takeovers (Meulbroek, 1992). Agarwal and Singh (2006) tested the insider trading prior to merger announcement in a developing economy, i.e. India and found existence of possible insider trading prior to merger announcements.

The extent to which the price run-up prior to the official announcement date is due to illegal insider trading is inconclusive. Some of the price run-up may reflect rumours or legitimate predictions by professional analysts. Jarrell and Poulsen (1989) and Aitken and Czernkowski (1992) provide evidence that rumours do account for a significant proportion, if not all, of the abnormal returns observed prior to the official announcement date. The price run-up may be due to the legitimate research and analysis of corporate information and could be attributed to a well functioning market. This finding indicates that the previous studies may have substantially overstated the extent of insider trading.

Meulbroek (1992) observes the price run-up prior to public disclosure of takeover announcements by examining illegal insider trades detected by the Securities and Exchange Commission (SEC) in the United States. Meulbroek accounts for the impact of rumours in her sample and finds that almost half of the pre-announcement stock price run-up observed before takeovers occurs on insider trading days. Hence, insider trading does not generate all of the price movement prior to the official public disclosure of the takeover, but it does account for a significant proportion. The validity of these prior studies cannot be discounted entirely, solely based on the findings by Jarrell and Poulsen (1989) and Aitken and Czernkowski (1992).

Secondly, providing that insider trading is illegal, insiders will try to hide their trading in securities so as not to get caught. Thus, they may communicate the information to 
third parties to trade on their behalf in order to try and escape detection. Therefore, despite the price run-up in shares not being a direct result of registered insiders trading in securities prior to an announcement, it may still be considered insider trading and contravene the relevant legal prohibitions.

Other studies investigating insider trading prior to specific corporate announcements include Elliot, Morse and Richardson (1984), Givoly and Palmon (1985) and Sivakur and Waymire (1994). These studies conclude that even though insiders generally have information before the public, only a small proportion of insider trades may be related to firm specific announcements. Specifically, Elliot, Morse and Richardson (1984) study abnormal returns generated before and after the public disclosure of information concerning dividends, earnings, bond ratings, mergers, and bankruptcies. They theorize that if insiders are exploiting their access to information received before the public, then insider buying activity should precede public disclosure of good news and selling activity should precede public disclosure of bad news. Whilst their results indicate that insiders do generally use private information in a profitable manner, there is no apparent abnormal pattern surrounding public announcements. This doesn't necessarily mean that insider trading does not exist during this period. Rather, insiders may adopt a passive strategy whereby the use of private information may be subtle. Insiders may delay buying or selling shares until after the public release of information, a strategy that may be no less profitable, though this way their trading cannot be classified as insider trading and consequently does not contravene the law.

In the USA, insider purchases have been more profitable than sales (Baesel and Stein, 1979; Nun et al. 1983; Seyhun, 1998; Lakonishok and Lee, 2001) and there is a positive trading volume/leverage impact on profitability (Seyhun, shall (2002), who find that an increase in the volume of insider purchases was associated with an increase in abnormal returns, but this was not the case for insider sales. Lakonishok and Lee (2001) argue that this is because insiders have many reasons to sell, which include liquidity, rebalancing and diversification, and these are not always undertaken based on price sensitive inside information.

Lorie and Neiderhoffer (1968), Jaffe (1976) and Finnerty (1976), among others, all adopt an intensive trading criterion and conclude that insiders in the U.S. do earn 
significant abnormal returns by trading on the securities of their own firms. That is, insiders are better informed about their own companies’ prospects and trade profitably based on this information. Jaffe (1976 p.428.), in particular, asserts that the occurrence of profitable insider transactions implies that "trading on inside information is widespread" and "insiders actually do violate security regulations”.

Studies also suggest that directors time their trades; purchases (sales) take place after abnormal share price decreases (increases), following which the fortunes of the companies reverse. Lin and Howe (1990) and Hillier and Marshall (2002), among others, observed the price reversal effect in the over the counter (OTC) market and on the London Stock Exchange respectively. Insiders are motivated to trade based on not only the likely future performance of the company, but also on the company's past performance, so as to maximise abnormal returns.

In the case of Australia Brown and Foo (1997) and Anand et al. (2002) find that directors' selling transactions, not purchase transactions, are associated with abnormal returns. Tomasic (1991) conducted the only direct examination of illegal insider trading in Australia. He interviewed key players in the finance industry including brokers, lawyers, merchant bankers, financial journalists, and officers, among others, who offered their perceptions of the incidence of insider trading. He found that insider trading occurs predominantly in small speculative stocks and is likely to be undertaken by directors. He also contends that illegal insider trading is likely to occur in the market for shares rather than options. ${ }^{2}$

Watson and Young (1998) examined insider trading surrounding takeover announcements. Consistent with the prior studies conducted in the U.S. they found a significant price run-up prior to the official announcement of the takeover. Their study also indicates that directors appear to blatantly disregard the law in the period immediately prior to the announcement.

Debate exists among the academic community as to whether insider trading is actually beneficial or harmful to society. Manne (1966) in his seminal book "Insider Trading

2 This result is not surprising considering the Australian options market was not particularly liquid in 1991. 
and the Stock Market” stunned the academic community by proposing the deregulation of insider trading.

Well-known economist and Nobel Prize winner Milton Friedman (2003) aptly described this argument in his statement "you want more insider trading, not less. You want to give the people most likely to have knowledge about deficiencies of the company an incentive to make the public aware of that”. According to this reasoning, corporate collapses such as HIH and Enron would have been brought to the public's attention much sooner.

Further, Manne (1966) argues that allowing insider trading is an effective means of compensating corporate agents for innovations. The entrepreneur can purchase the firm's shares before the innovation is announced to the market and sell the shares after the resultant price increase. This forms an effective compensation scheme whereby the compensation is directly linked to the value of the innovation to the firm. Carlton and Fischel (1983) cite that this method is more effective than constant renegotiation of fixed contracts and allows the individual to tailor the compensation to the information he or she produces. As a result, this further increases the entrepreneur's incentive to develop more valuable innovations. Society and the firm benefit through the additional information produced that is of value to the firm.

Whilst these studies generally indicate that insiders do profit from trading when in possession of non-public information, the studies do not attempt to identify who trades on the inside information. This may partly be overcome with the disclosure of directors' trades.

\section{Data}

Information on directors' trades was obtained from the original Appendix 3Y database compiled by DatAnalysis. As required by the Corporations Law, directors must disclose any changes in their interests of the company to the ASX within five business days. Directors fulfil this requirement by completing an Appendix 3Y, which is then submitted to the ASX. After the information has been disclosed to the ASX, the full text of the announcement is made publicly available. 
Data was collected for all changes in directors' holdings reported to the ASX during the six-months from July to December 2005. Information was obtained from the original disclosure notices regarding the type of trade, volume of the transaction, nature of the interest, date of the transaction, and the date of disclosure. Care has been taken to include all trades disclosed during this period; however, the data does not include changes in directors' interests that were reported after 31 December 2005, even though they may pertain to the sample period.

Transactions were removed from the sample if (i) more than one transaction type was stated in the change of director's interest notice, but the number of shares was indistinguishable between the two types, (ii) the trade involved an amendment in subsequent disclosures and (iii) the trade specifically disclosed the reason for the change in holdings. If no transaction type was disclosed, it was assumed to be on an on market trade. Similarly, in cases where no date of change was reported, the date of change was taken to be the date of disclosure. Trades that extended over a period of time but were not disclosed separately were recorded as at the date of the first transaction.

To avoid double counting, where two or more trades by different directors involved the same parcel of indirectly held shares, all but one of the transactions were removed from the sample. That is, where two or more directors of the same company reported a change in holdings of the same amount on the same day, the nature of the interests was examined. If the nature of the interest was indirect for both directors, only one of the transactions was retained. Similarly, multiple trades on the same day by the same director of the same company were combined together to form a total change in holdings.

Given that not all directors' trades are based on inside information, only on market transactions were included in the sample. Thus, trades that are not traditionally motivated by the possession of possible inside information were removed. This included off market trades, dividend reinvestment schemes, conversions of options, share purchase plans and rights issues. Likewise, to reduce the potential for including trades for reasons such as diversification or taxation, an intensive trading criterion was imposed. If a company's stock exhibits intensive trading in the same direction by 
directors, it is likely that the trades are information motivated. In order to be included, it was required that over the given sample period, four or more directors buy (sell) shares and no director takes an opposing action ${ }^{3}$. This requirement is consistent with previous empirical research conducted by Lorie and Neiderhoffer (1968) and Jaffe (1976).

A survivorship criterion was imposed to only include companies that had available share price and volume data for the 160 days before and after the date of trade. Companies were also removed from the sample if market capitalisation data was not available as at 28 September 2006 and if the company was suspended from trading at any time during the sample period. This was determined by examining the volume and price data for each firm. If a company experienced an unusual period of zero returns and volume their company announcements were examined to determine if this was due to a trading halt. ${ }^{4}$ No adjustments have been made to account for thin trading and thus it may be a problem affecting many of the companies, especially in the case of smaller companies.

\section{Research Methodology:}

\subsection{Abnormal Return}

The stock price behaviour surrounding directors' trades was examined using an event study method where the date of interest was the date of director's trade. To avoid misspecification arising from overlapping event periods, the sample was further reduced. Lyon, Barber and Tsai (1999) cite the only way to overcome this problem is to purge the observations of overlapping returns. Thus, of the companies that experienced intensive trading, only one trade was selected in order to calculate profitability of possible insider trading. Selection was based on the trade of greatest volume and the date of change, so as to capture the date of the other trades in the surrounding event window.

There is difficulty involved in detecting insider trading, both in the market place and by individual directors. Thus, the presence of insider trading may be inferred from the existence of abnormal returns - a practice that is generally accepted in the finance

\footnotetext{
${ }^{3}$ The intensive trading criteria could have been over a shorter period, such as one month, however, Lakonsihok and Lee (2001) note that measures calculated over longer time horizons seem to have a somewhat greater predictive power. A shorter time period would result in many firms having no trades.

${ }^{4}$ Although care has been taken to remove companies that were suspended from trading during the period, because of the subjective nature of this measure, some companies that were suspended may still remain in the sample.
} 
literature. The calculation of abnormal returns requires the use of a benchmark in order to isolate the unusual performance of a specific asset by comparing the expected returns with actual returns.

For each of the securities, daily rates of return were calculated: ${ }^{5}$

Where;

$$
R_{i, t}=\ln \left(P_{i, t}\right)-\ln \left(P_{i, t-1}\right)
$$

$\mathrm{R}_{\mathrm{i}, \mathrm{t}} \quad=$ return of security $\mathrm{i}$ on day $\mathrm{t}$

$\mathrm{P}_{\mathrm{i}, \mathrm{t}} \quad=$ the adjusted closing price for security $\mathrm{i}$ on day $\mathrm{t}$

$\mathrm{P}_{\mathrm{i}, \mathrm{t}-1} \quad=$ the adjusted closing price for security $\mathrm{i}$ on day $\mathrm{t}-1$

Rozeff and Zaman (1988) indicate that firm size affects the abnormal returns from insider trading and must be considered when selecting an appropriate model. Dimson and Marsh (1986) propose that the size effect can be overcome by constructing a set of diversified control portfolios for companies in different capitalisation classes. This method is preferable to the Capital Asset Pricing Model (CAPM) or a market model because it specifically accounts for firm size and is non-parametric in its approach. The use of this method is consistent with Lin and Howe (1990) and is defined as the size decile adjusted return:

$$
A R_{i, t}=R_{i, t}-R_{D i, t}
$$

Where:

$\mathrm{AR}_{i, t}=$ abnormal return of stock $\mathrm{i}$ on day $\mathrm{t}$

$\mathrm{R}_{i, t} \quad=$ price relative of stock $\mathrm{i}$ on day $\mathrm{t}$

$\mathrm{RD}_{i, t}=$ price relative of equally weighted portfolio of stocks in the same size decile $\mathrm{D}$ as stock i on day $\mathrm{t}$

This model measures the abnormal return of a firm which may be due to intensive insider trading relative to the return of similar sized companies during the period.

All companies listed on the ASX were ranked according to market capitalisation as at 28 September $2006^{6}$ and divided into three separate control portfolios according to size: small, medium and large. Only companies that were trading for the duration of

\footnotetext{
5 We concentrate on daily rates of return rather than monthly because it facilitates a closer scrutiny of the impact of insider trading.

${ }^{6}$ Historical market capitalisation data was unavailable for the event period windows.
} 
the event window with available volume, share price and market capitalisation data were included. Large companies were defined as Top 150 companies according to their market capitalisation; Medium companies are Top 500 companies excluding those in the Top 150; and Small companies are those outside the Top 500. Daily returns for each portfolio were calculated by averaging the daily returns of the securities in the portfolio. The control portfolios include the sample firms, an approach consistent with a "naïve" investor. The control portfolio reflects the buy and hold return that a naïve investor could have earned simply by investing in a welldiversified portfolio of stocks, of similar size, without any special information.

Average abnormal returns were calculated cross-sectionally up to 160 days before and after the date of trade: ${ }^{7}$

$$
A A R_{t}=\frac{\sum_{i=1}^{n} A R_{i, t}}{n}
$$

Where;

$\mathrm{AAR}_{t}=$ Average Abnormal Return on day $\mathrm{t}$

$\mathrm{AR}_{i, t}=$ Abnormal Return of stock i on day $\mathrm{t}$

The average abnormal returns were then cumulated over several event windows to form the cumulated average abnormal returns (CAR) for the purchases and sales sub samples. The cumulative abnormal return was also calculated after stratifying the purchases and sales sub samples into small, medium and large categories.

$$
\operatorname{CAR}_{\left(t_{1}, t_{2}\right)}=\sum_{t-t_{1}}^{t_{2}} A A R_{t}
$$

Where;

$C A R_{\left(t_{1}, t_{2}\right)}=$ Cumulative Average Abnormal Return over the period t1 to t2 $\mathrm{AAR}_{t}=$ Average Abnormal Return on day $\mathrm{t}$

\subsection{Abnormal Volume}

\footnotetext{
${ }^{7}$ Pre-trade returns were examined because they can give significant insight into the reasons why directors trade and their ability to time the market.
} 
In addition to stock return data, abnormal volume can indicate the possession of inside information and the dissemination of information contained in directors' trades to the market. Volume can also act as a signal provider to the market and may help identify to outsiders whether the director's trade is information motivated. In the market microstructure literature, high trading volumes are associated with the release and reception of information. Abnormal volume was calculated in a similar way to abnormal return and requires the use of a benchmark. Gao and Oler (2004) propose a method of calculating abnormal volume that accounts for firm specific (time series) and market wide (cross-sectional) factors: ${ }^{8}$

$$
\text { Abnormal Volume }_{i, t}=\frac{V_{i, t}-V_{i, \text { normal }}}{V_{i, \text { normal }}}-\frac{V_{D, t}-V_{D, \text { normal }}}{V_{D, \text { normal }}}
$$

Where;

$\mathrm{V}_{\mathrm{i}, \mathrm{t}} \quad$ = Volume of company $\mathrm{i}$ on day $\mathrm{t}$

$\mathrm{V}_{\mathrm{i} \text {, normal }}=$ Average daily volume for firm i over estimation period

$\mathrm{V}_{\mathrm{D}, \mathrm{t}} \quad=$ Average volume of equally weighted portfolio of stocks in the same size decile $\mathrm{D}$ as stock i on day $\mathrm{t}$

$\mathrm{V}_{\mathrm{D} \text {, normal }}=$ Average volume of equally weighted portfolio of stocks in same decile as stock i over the estimation period

Average abnormal volume was calculated cross-sectionally for the 160 days before and after the date of trade:

Where;

$$
A A V_{t}=\frac{\sum_{i=1}^{n} A V_{i, t}}{n}
$$

$A A V_{t}=$ Cross-sectional Average Abnormal Volume at time $t$

$A V_{i, \mathrm{t}}=$ Abnormal Volume of company $i$ on day $t$

The cross-sectional average abnormal volume (AAV) was calculated for the purchases and sales sub-samples and after stratifying the sample according to company size.

8 Whilst this method has received criticism, time constraints preclude additional robustness checks. 


\section{Empirical Results}

\subsection{Abnormal Return}

\subsubsection{Timing of Directors' Trades}

Stock price behaviour surrounding directors' trades is displayed for both purchases and sales in Figure 1 for the 160 days before and after the date of trade. From this, it can be seen that not only do directors earn abnormal returns from their trades, but also on average time their trades nearly to perfection. The graph exhibits a price reversal effect; sales occur after a period of good performance and purchases occur after a period of poor performance, at which time the trend is reversed. From approximately 80 days before through to the day of the transaction, abnormal returns on purchases of directors' firms on average under perform the market. On the day of the buy transaction the abnormal returns on shares of the directors' companies begin to outperform the market. Can we say that directors have an idea before hand that prices are going to go north? It seems it is not so easy to establish. Sale transactions generally exhibit the opposite pattern. This is consistent with prior literature that discredits the strong form of market efficiency; prices do not contain private information.

FIGURE 1. 160 day Pre- and Post-trade Cumulative Abnormal Returns All Trades

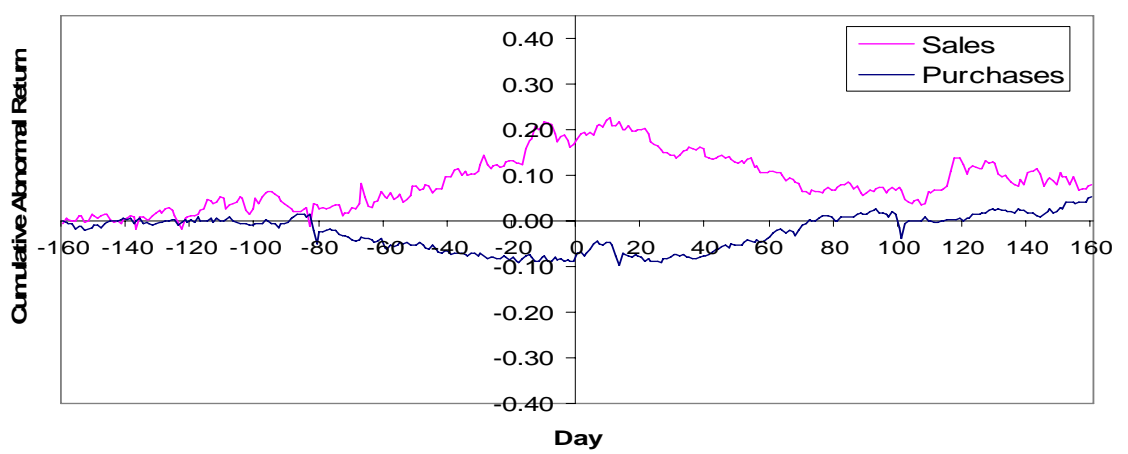

Table 1. 160 day Pre- and Post-trade Cumulative Abnormal Returns Breakdown by Company Size-

\begin{tabular}{ccccc}
\hline Event Period CAR & All & Small & Medium & Large \\
\hline & & & & \\
Panel APurchases & & & & \\
\hline$[-160: 0]$ & -0.0720 & 0.0041 & -0.3065 & -0.0381 \\
{$[+1:+160]$} & 0.1256 & 0.1788 & 0.0406 & -0.0386 \\
\hline & & & & \\
Panel Bsales & & & & \\
\hline$[-160: 0]$ & 0.1808 & 0.2323 & 0.1186 & 0.2157 \\
{$[+1:+160]$} & -0.1020 & -0.0641 & -0.0882 & -0.1755 \\
\hline
\end{tabular}


Whilst the results for all trades appear to be straightforward, when stratified according to size, the results are not so clear and can be seen in Figures 2 to 4. Medium, small and large companies all exhibit a price reversal effect for sales, where it is apparent that directors time their trades and earn substantial abnormal returns, with varying degrees of profitability.

Purchases on the other hand, for all firms, do not generally exhibit a price reversal effect; however they do still on average exhibit patterns consistent with directors timing their trades. Pre-transaction abnormal returns of purchases by directors of small companies fluctuate around zero. Post-trade abnormal returns show a positive trend, however, starting around the day of the director's trade. Pre-transaction abnormal returns are not necessary in illustrating the timing ability of the directors (Mitchell and Watson, 2004). Similarly, directors' trades of medium companies do not exhibit a price reversal effect. Like sales, pre-trade abnormal returns are negative; however, the post-trade abnormal returns are approximately zero for the following 150 days. Whilst directors' purchases are not profitable, they are timed to avoid significant losses. Purchases by directors of large companies do not show any apparent trend. Abnormal returns are approximately the same over the pre- and posttrade periods.
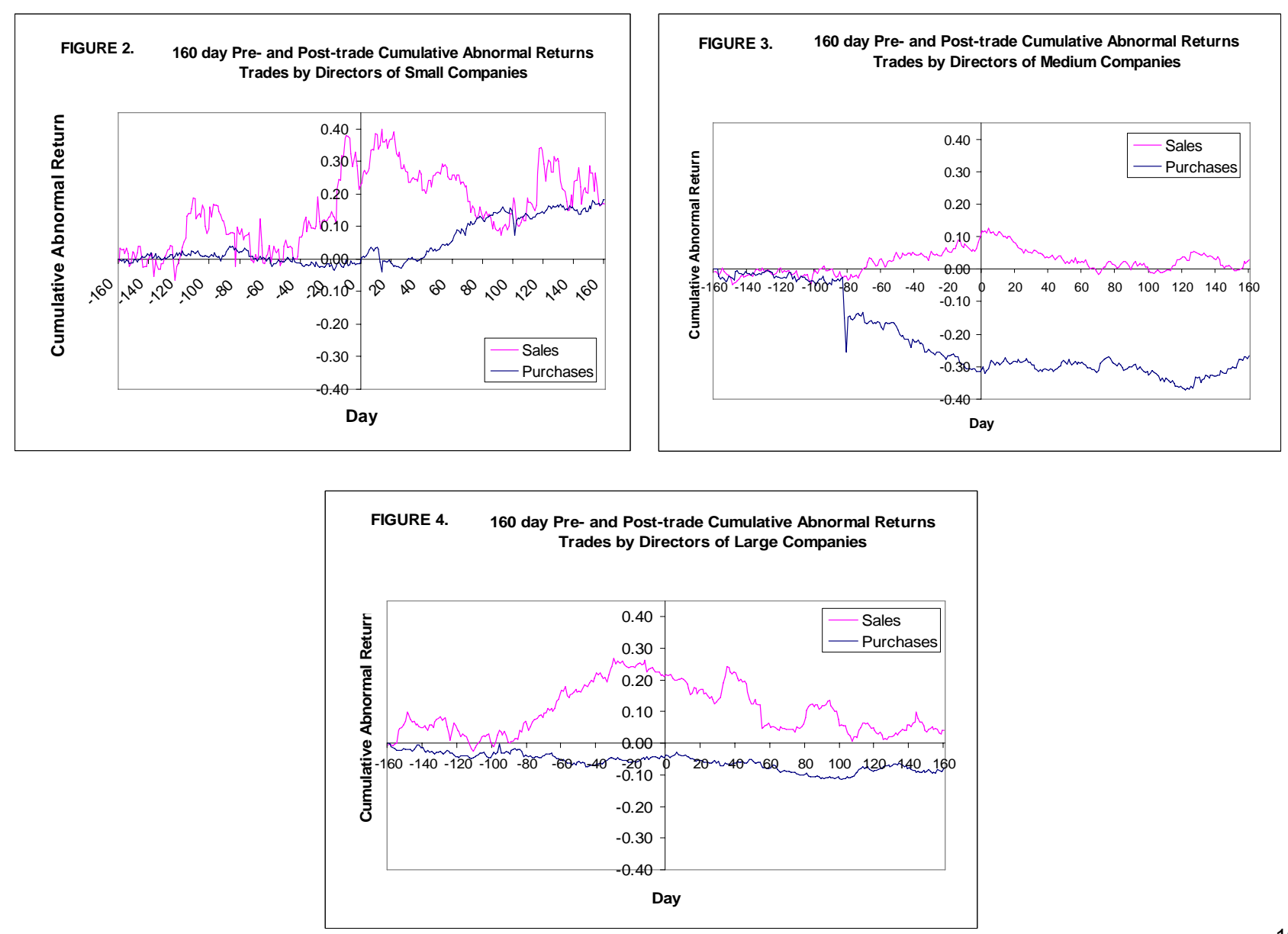


\subsubsection{Profitability in 160day Pre- and Post-trade Period}

Profitability of trades varies significantly according to the type of trade and size of the company and is represented by the post-trade cumulative abnormal returns as shown in Table 3. Directors may earn abnormal returns if stock prices rise abnormally after their purchases or if stock prices decline abnormally after their sales. Negative posttrade profits of directors' sales are taken to be profits to directors in the sense that relative losses are avoided. When all trades are combined, purchases (12.56\%) are more profitable than sales (10.20\%) over the 160 days after the trade date; however, the difference does not appear to be economically significant. This finding is consistent with previous literature in the United States and the United Kingdom. Interestingly, it contradicts the previous empirical research conducted in Australia.

Again, this finding is inconsistent when stratified by company size. Purchases (17.88\%) by directors of small companies are significantly more profitable than sales (6.41\%). Trades by large and medium companies have the opposite effect. Sales (17.55\%) by directors of large companies are more profitable than purchases ($3.86 \%)$, as are trades by directors of medium companies (8.82\% and $4.06 \%$ for sales and purchases respectively). The finding of post-trade abnormal returns is in accord with the results of previous studies (based on different samples). For example, Givoly and Palmon (1985) report cumulative abnormal returns of approximately $8.6 \%$ for purchases and $11.53 \%$ for sales over the 240 days after the trade. They estimate abnormal returns for an eight-month holding period of approximately 8\% (an average of reported results for sell and buy transactions).

Although trades by directors of small companies are consistently profitable, there is little evidence that profitability is inversely related to firm size. The substantial profitability of sales by directors of large companies indicates that large companies are not necessarily more efficiently priced or face greater scrutiny than their small company counterparts.

\subsubsection{Profitability in 90 day Pre- and Post-trade Period}

Similar findings can be observed in Figure 5 over the 90-day period before and after the date of the director's trade. Similar to the 160-day findings, sales exhibit a price reversal, as do purchases, except for trades by directors of large companies. Whilst the pattern is the same as that observed over the 160-day period, the profitability of trades 
over this shorter horizon, as shown in Table 2, allow us to provide further insight into the trading patterns of directors and their possible holding periods.

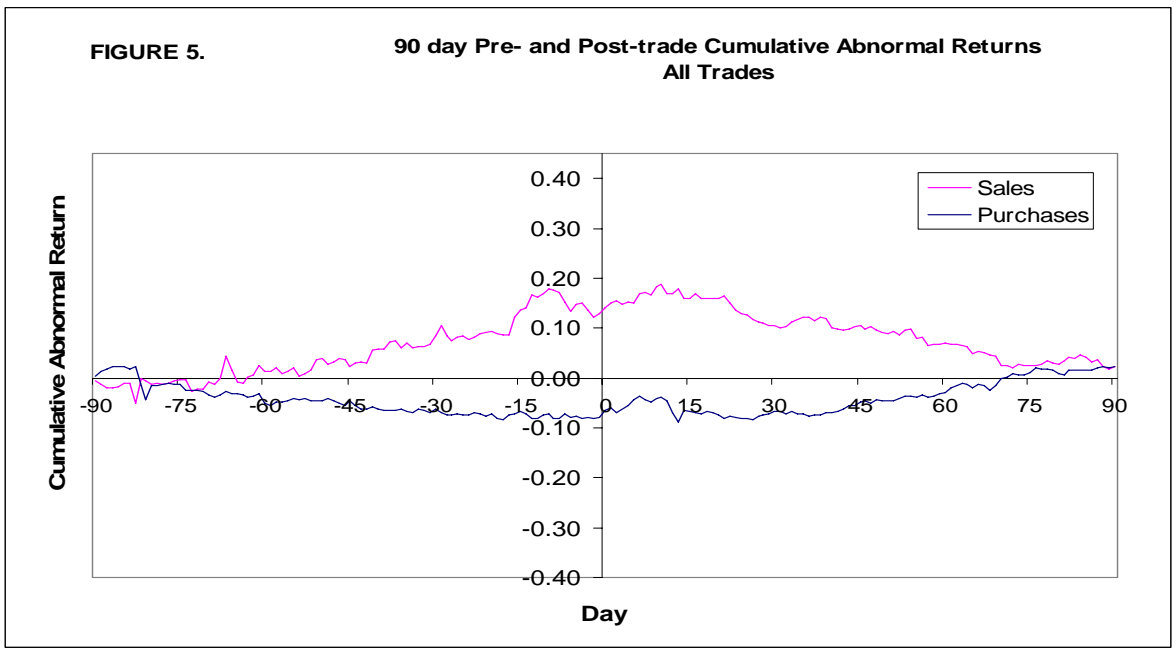

Table 2. 90 day Pre- and Post-trade Cumulative Abnormal Returns

\begin{tabular}{ccccc} 
& & \multicolumn{3}{c}{ Breakdown by Company Size } \\
\cline { 3 - 5 } Event Period CAR & All & Small & Medium & Large \\
\hline & & & & \\
Panel APurchases & & & & \\
\hline$[-90: 0]$ & -0.0650 & -0.0042 & -0.2636 & -0.0109 \\
{$[+1:+90]$} & 0.0880 & 0.1393 & 0.0067 & -0.0715 \\
\hline & & & & \\
Panel B. Sales & & & & \\
\hline$[-90: 0]$ & 0.1416 & 0.1139 & 0.1220 & 0.2112 \\
{$[+1:+90]$} & -0.1198 & -0.1458 & -0.1125 & -0.0971 \\
\hline
\end{tabular}

The abnormal returns in the 90-day pre-trade period for purchases are approximately the same as those earned over the 160-day period as shown in Panel A of Table 3. This indicates that the majority of abnormal returns are earned closer to the trade date and that during the 90-day to 160-day period abnormal returns are approximately zero. It appears that private information is evident in the market up to 90 days before the actual date the director trades, but not over a longer horizon. Over the post-trade period for purchases the abnormal returns are only slightly larger over the longer time period, except for trades made by directors of large companies. Directors have an ability to predict the future performance of a firm over a longer period of time. Directors are likely to have holding periods of at least 160days.

The findings are similar for sales. The abnormal returns earned in the 90 days prior to the trade are approximately the same as those earned in the 160 days before the trade. 
It appears that directors of medium and large companies have inside information up to 90 days before the actual date of trade, whereas directors of small companies have this information over a longer period of time, before it is eventually traded on.

In the post-trade period, the abnormal returns earned over the 90 days preceding the trade are greater than the abnormal returns earned over the following 160 days, except for trades by directors of large companies. These results indicate that bad news is incorporated into prices much sooner than good news.

\subsubsection{Profitability in Short-Term}

Profitability of trades in the short term i.e. over the following twenty days, do not appear to be significant for any trades, except small sales, which have a cumulative abnormal loss over this period of $13.66 \%$, as shown in Table 3. This finding has significant implications. Directors' trades have little explanatory power in predicting returns over a short horizon such as one month, suggesting that directors are not likely to be day traders or fly by night operators.

The finding that directors' trades are profitable in the long run but not over a short horizon is again consistent with studies conducted in the United States [Givoly and Palmon (1985) and Lakonishok and Lee (2001)]. It is important to note that trading regulations differ between the two countries. The Securities and Exchange Commission (SEC) in the United States prohibits insiders from profiting on round-trip trades completed within a six-month period. Any profits made from such a transaction must be disgorged and returned to the corporation ${ }^{1}$. No such regulation exists in Australia. Whilst this may explain the results of the studies conducted in the United States, it cannot explain the results of our study. One possible reason for this observation could be that directors are still wary about their legal obligations. If they were to trade based on a forthcoming event, this may subject them to unwanted scrutiny by ASIC. The presence of abnormal returns over a relatively longer time horizon and not over the short term also suggests that directors are not enticed to trade based on the forthcoming disclosure of a specific event (Givoly and Palmon, 1985).

${ }^{1}$ s16(b) of the Securities and Exchange Act 1934 
Table 3. 20 day Pre- and Post-trade Cumulative Abnormal Returns

\begin{tabular}{ccccc}
\multicolumn{5}{c}{ Breakdown by Company Size } \\
\hline Event Period CAR & All & Small & Medium & Large \\
\hline Panel A.Purchases & & & & \\
\hline$[-20: 0]$ & 0.0125 & 0.0258 & -0.0300 & 0.0216 \\
{$[+1:+20]$} & -0.0085 & -0.0179 & 0.0220 & -0.0167 \\
\hline & & & & \\
Panel B.Sales & & & & \\
\hline$[-20: 0]$ & 0.0494 & 0.1024 & 0.0514 & -0.0247 \\
{$[+1:+20]$} & 0.0182 & 0.1366 & -0.0379 & -0.0460 \\
\hline
\end{tabular}

Overall, only purchases by directors of small companies show any significant abnormal return. Sales, on the other hand are profitable by directors of all companies. Whilst purchases by directors of medium companies are not profitable, they are timed to avoid significant negative abnormal returns and could be an indication that the period of poor performance has ended.

\subsubsection{Mimicking Trades by Outsiders}

Given that directors do generally earn abnormal returns and time their trades, their trading contains a certain degree of information regarding the future long-term performance of the firm. Therefore, it would be expected that when the director discloses the change in their interest, this would be fully incorporated into share prices on the day of disclosure. So, outsiders should not be able to mimic the trading patterns of directors and earn any abnormal returns on this publicly available information.

Specifically examining the abnormal returns earned in the post-disclosure period has tested this, the results of which can be seen in Table 4.

Table 4. Post-disclosure Cumulative Abnormal Returns (CAR)

\begin{tabular}{ccccc} 
& & \multicolumn{3}{c}{ Breakdown by Company Size } \\
\cline { 3 - 5 } Event Period CAR & All & Small & Medium & Large \\
\hline & \multicolumn{4}{c}{} \\
Panel APurchases & & & & \\
\hline$[+5:+90]$ & 0.0778 & 0.1236 & 0.0070 & -0.0695 \\
{$[+5:+160]$} & 0.1153 & 0.1631 & 0.0409 & -0.0366 \\
\hline & & & & \\
Panel BSales & & & & \\
\hline$[+5:+90]$ & 0.1318 & 0.1827 & 0.1187 & 0.0857 \\
{$[+5:+160]$} & 0.1140 & 0.1010 & 0.0944 & 0.1641 \\
\hline
\end{tabular}

*Returns for directors' sales are converted to a "loss avoided" interpretation by multiplying them by -1 .

It is apparent that in purchase trades, except of directors of small companies none other has much abnormal return in a period up to 90 days. Outsiders do not recognise 
that directors' trades convey information regarding the future long-term profitability of their companies.

The information contained in directors' trades should be reflected in the share price up to five trading days after the change in holdings, as required by law. Not all directors disclose their trades within this time period. ${ }^{2}$ The average time between date of change and date of disclosure is approximately five calendar days for all trades and does not differ according to firm size, assuming that on average directors do conform to their reporting requirements. Accordingly, for our sample, abnormal returns should not be evident starting five days after the date of the director's change in holdings.

Outsiders mimicking the trading patterns of directors can still earn significant abnormal returns up to $16.41 \%$ (sales trade) in the 160 -day post-announcement period. For sales, in order to mimic the trade the outsider must already own shares in the company. Alternatively, this could be interpreted as a signal of when not to purchase shares. Short selling is not a viable strategy for mimicking directors' sales, in that a short position must be settled within three days; however trades are only profitable over a relatively longer period of time. The finding that abnormal returns are predictable to some extent has important market efficiency implications and suggests that the market is not efficient in the semi-strong form; abnormal returns can be earned by trading on publicly available information.

\section{$\underline{5.2 \text { Abnormal Volume }}$}

As previously mentioned, abnormal volume provides further insight into the dissemination of directors' trades into the market and the trading patterns of both directors and outsiders. If outsiders follow the disclosure of directors' trades, it would be expected that volume would substantially increase on the day of disclosure. If this were the case, it would seem that outsiders do pay attention to the trading patterns of directors and they consider that directors' trades convey a certain degree of information.

\footnotetext{
2 Depending on the nature of non-disclosure the ASX will take appropriate action usually requiring the company or director to disclose the reason for the non-disclosure and the steps in place to ensure future compliance. If the listed entity continues not meeting the requirements of listing rule 3.19A, the ASX will refer the matter to ASIC for further action under s205G of the Corporations Act 2001 (ASX 2005).
} 
The abnormal volume is displayed in Table 5 and graphically in Figure 5 for the 160 days before and after the date of trade. Panel A of Table 5 indicates that abnormal volume for directors' purchases on average increase substantially on the day before and the day after the date of trade. Panel B of Table 5 indicates that abnormal volume increases substantially on the day before the director's sale through to the day after the trade. Apart from transactions by directors of large companies this is consistent when stratified according to company size, although reason for this finding is unclear.

Table 5. Abnormal Volume

\begin{tabular}{|c|c|c|c|c|}
\hline \multirow[b]{2}{*}{ Event Day } & \multirow[b]{2}{*}{ All } & \multicolumn{3}{|c|}{ Breakdown by Company Size } \\
\hline & & Small & Medium & Large \\
\hline \multicolumn{5}{|c|}{ Panel A.Purchases } \\
\hline-160 & -0.21 & -0.27 & -0.09 & -0.39 \\
\hline-90 & -0.21 & -0.27 & 0.01 & -0.37 \\
\hline-20 & 0.11 & -0.18 & 0.34 & 0.25 \\
\hline-3 & 0.01 & 0.00 & 0.38 & -0.25 \\
\hline-2 & 0.19 & 0.21 & 0.37 & -0.19 \\
\hline-1 & 1.01 & 1.06 & 1.84 & 0.25 \\
\hline 0 & 0.20 & 0.31 & 0.40 & 0.64 \\
\hline+1 & 4.98 & 5.45 & 4.03 & 2.20 \\
\hline+2 & 0.53 & 0.46 & 1.12 & 0.55 \\
\hline+3 & 0.50 & 0.25 & 0.43 & -0.07 \\
\hline+4 & 0.12 & 0.00 & 0.15 & -0.08 \\
\hline+5 & -0.15 & -0.02 & -0.13 & -0.02 \\
\hline+6 & -0.16 & -0.26 & 0.24 & -0.46 \\
\hline+20 & -0.44 & -0.44 & -0.36 & -0.27 \\
\hline+90 & -0.32 & -0.30 & -0.34 & -0.41 \\
\hline+160 & 0.23 & 0.45 & -0.05 & 1.38 \\
\hline \multicolumn{5}{|l|}{ Panel BSales } \\
\hline-160 & -0.23 & 0.20 & -0.78 & 0.35 \\
\hline-90 & -0.36 & -0.98 & 0.34 & -0.58 \\
\hline-20 & 0.01 & -0.37 & 0.63 & -0.55 \\
\hline-3 & 0.64 & 1.89 & 0.25 & -0.40 \\
\hline-2 & 0.55 & 0.53 & 0.57 & -0.46 \\
\hline-1 & 1.58 & 2.52 & 1.47 & 0.02 \\
\hline 0 & 2.20 & 5.92 & 0.72 & -0.23 \\
\hline+1 & 7.92 & 3.96 & 16.09 & -0.57 \\
\hline+2 & 0.79 & 2.02 & 0.80 & -0.69 \\
\hline+3 & -0.18 & -0.59 & 0.07 & -0.49 \\
\hline+4 & 0.26 & 0.70 & 0.37 & -0.44 \\
\hline+5 & 1.49 & 2.55 & 1.60 & -0.56 \\
\hline+6 & -0.12 & -0.36 & 0.42 & -0.77 \\
\hline+20 & -0.47 & -0.70 & -0.02 & -0.69 \\
\hline+90 & -0.50 & -1.04 & -0.34 & 0.27 \\
\hline+160 & -0.48 & -0.84 & -0.53 & -0.50 \\
\hline
\end{tabular}




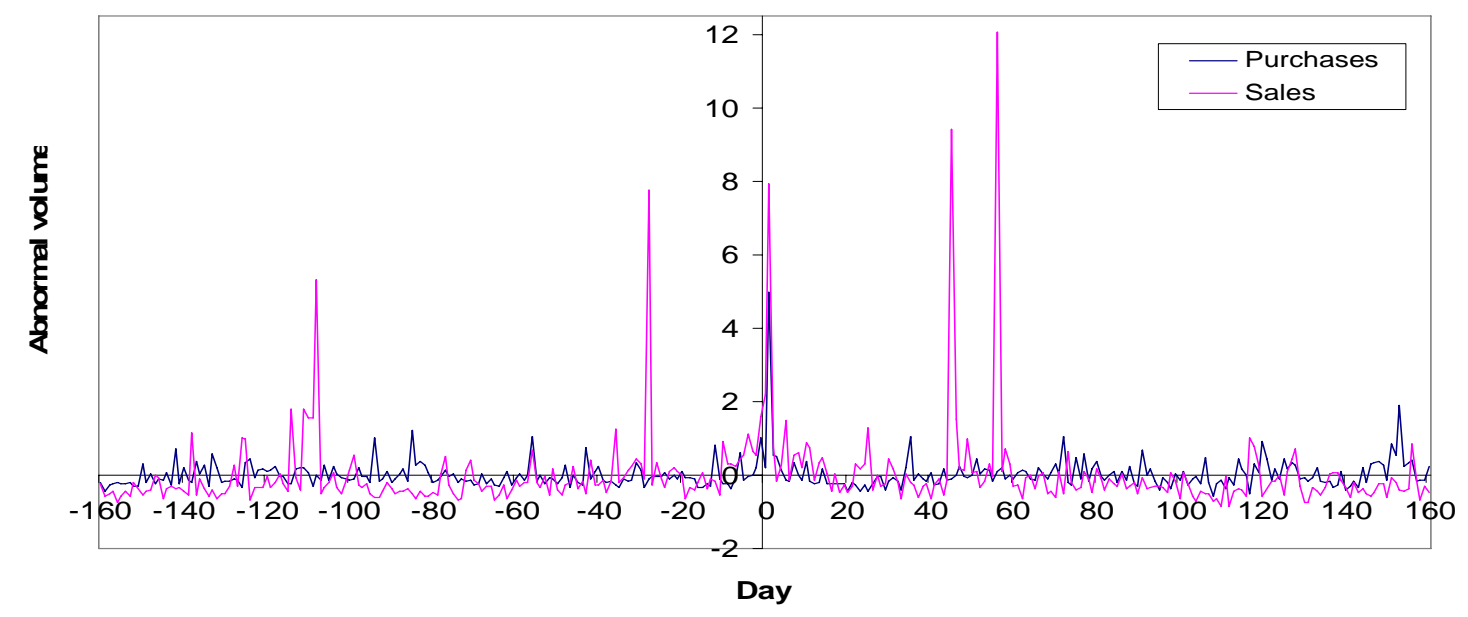

In the period before and after the trade date, apart from the substantial increase immediately surrounding the date of the trade, abnormal volume appears to fluctuate approximately around zero. ${ }^{3}$ Again, this finding has a number of implications. Directors' trades do not directly drive the substantial increase in volume. The volume starts to increase before the actual date of the director's trade and on the day following the trade.

Trading by informed outsiders may also explain the increase in volume prior to the trading by the director. The director may have expressed their intention to trade to other third parties who trade on this information before the director does and who do not have to report. Intuitively this does not make much sense. If a director were to inform others about their trading it would most likely be after the director has traded so as to maximise their own profits. On the other hand, it could be driven by other informed investors (may be near and dear of directors) who are privy to the nonpublic information, other than leaks by the directors themselves, and who do not have to report their trades. Either explanation would likely explain the increase in volume on the day following the trade.

An alternative explanation is that directors try to mask their trades by trading when the market is noisy and other uninformed investors are driving up volume. If private information becomes disseminated it loses its value to the informed agent. Therefore,

${ }^{3}$ The reasons for the apparent fluctuations on days $-108,-28,+45$ and +56 are unclear. 
in the process of trading, the informed strive to maintain privacy of their information, although this is only evident for purchase transactions.

The finding that volume substantially increases on the day of trade for sales but not purchases indicates that directors are more likely to purchase shares in smaller denominations than sales in an attempt to hide their trading. It also supports the theory that informed traders transmit information by trading large amounts, a finding consistent with the previous observation that directors' sales are more profitable than their purchases.

Givoly and Palmon (1985) indicate that the mere occurrence of directors' trades, regardless of whether it is based on inside information, may generate abnormal returns. Since many investors closely watch directors' trades, their trading may trigger a wave of transactions in the same direction by outsiders. This in itself may generate the abnormal returns to insiders in the period following their trades. This does not appear to be the reason for the abnormal returns earned by directors in our sample and is apparent in Figure 5 by observing abnormal volume. Volume on the day of the trade and the following day substantially increases. Given that directors on average disclose their trade five calendar days after the date of the actual trade ${ }^{4}$, this indicates that outsiders do not drive the abnormal volume in reaction to the trade because they are as yet unaware of the change in interest.

It is also evident however, that volume significantly increases on the day of average disclosure for sales. This is noteworthy because it signifies that outsiders do pay attention to the trading of directors and mimic their trading. It appears however, that even though outsiders recognise that directors' trades convey information, this is not fully incorporated into prices.

The actual reason for the considerable increase in volume cannot be determined without further empirical research. It would be beneficial to calculate abnormal volume taking into account the actual volume traded by the director. This would help determine whether the director's trade accounted for a significant proportion of total

${ }^{4}$ See Gettler (2005) for contrary findings. 
volume and whether abnormal volume was driven primarily by the director's trade or by outsiders. It would also be beneficial to examine intra-day data and the occurrence of company announcements surrounding the date of trade.

The apparent under reaction by investors in response to directors' trades could also be explained by the nature of the disclosure. (Daniel, Hirshleifer et al., 2002) note that in providing information to investors, relevant information must be salient and easily processed; the form as well as the content is important and affects how well the information is absorbed. Investors may find the disclosure of directors' trades difficult to interpret. Not all trades are based on inside information and thus, investors must be able to discern the difference between trades in order to effectively mimic them promptly. This is especially likely to be the case in our study. Literature in Australia regarding effective trading strategies based on directors' trades is scarce, as are commercialised services that explicitly sell and interpret insider trading data. Investors may not know which trades to mimic and even whether this presents a profitable strategy.

\subsubsection{Interest in Sales versus Purchases}

The observation that sales are generally more profitable than purchases is not new; however, the reason has previously never been explored. The studies by Brown and Foo (1997) and Givoly and Palmon (1985) observe this effect, however they do not provide an explanation extending beyond methodology limitations in the prior literature. Whilst this may also be the case, it does not account for the large number of studies that have consistently found that the reverse is true, even when the same methodology has been used. The finding that purchases are more profitable than sales has an intuitive explanation. Purchases are made for only one reason, to make a profit, whereas sales may be driven by other underlying factors such as taxation, diversification, liquidity etc.

In essence, we contend that sales are more profitable than purchases because directors are loss averse, a finding that is explained in the following discussion. Standard utility theory assumes that preferences do not depend on current assets. That is, except for transaction costs, initial entitlements do not effect final allocations. Kahneman and Tversky (1991), however, through the conduction of experiments, have found 
substantial evidence to the contrary; initial entitlements do matter and investors have a different reaction to gains as opposed to losses.

Kahneman and Tversky's prospect theory describes how individuals evaluate losses and gains in respect to a given reference point. They contend that losses create more distress among investors than the happiness created by equivalent gains. In regards to sales by directors, the loss aversion is not in relation to the foregone shares because they are traded as initially intended. Rather, the director is loss averse to the future loss of return that would occur if the director were to hold onto the shares. Given the same expected variation in returns, a director is more likely to trade based on negative information rather than equivalent positive information.

Loss aversion can also explain the descriptive statistics ${ }^{5}$ whereby average trade size differs depending on the type of trade. Directors' trades display more urgency when faced with the possibility of a real loss and therefore they will trade in larger amounts. It is likely that directors will not sell all of their shares because they may be wary about the signal they send to the market and facing greater scrutiny from regulators. The trade size may represent a large proportion of their total holding.

It is also apparent that outsiders are loss averse, as evident from the abnormal volume displayed in Table 5. The substantial increase in volume on the day of disclosure for sales but not purchases indicates that outsiders are quick to update their beliefs in regards to potential losses, but they are slow to react to potential gains.

\section{Conclusions}

This paper's objective was two-fold: do directors earn abnormal returns and can outsiders, while mimicking the trading strategies of directors in their own company can make some abnormal return. We find that the answer to both of these questions is yes, particularly in the case of directors of small companies. The policy implications of our findings are clear; directors do appear to disregard the law and the current regulatory environment doesn't seem to deter them. ASIC may want to pay closer

\footnotetext{
5 See Appendix-A
} 
scrutiny to the trading activities of directors of small and medium companies and take further action if necessary.

We examined the abnormal share price performance surrounding directors' trades of intensive trading firms. Consistent with the majority of other studies we report that directors of small and medium companies on average outperform the market and seem to time their trades perfectly. Directors of these companies have an uncanny ability to time the market by trading when mispricing is greatest, and are able to predict the future performance of their firm in the 90 and 160 days following the trade because of their exclusive position. Upon investigation however, it is apparent that sales are more profitable than purchases. Sales consistently exhibit a price reversal effect; positive abnormal returns are earned prior to the sale and negative returns after it. Only sales by directors of small companies show any significant abnormal returns, however trades by directors of medium companies seems timed to avoid significant losses. It is likely that directors delay trading until the price is more favourable. Furthermore, there is little evidence to suggest that profitability is inversely related to firm size.

Directors' trades are profitable over the longer term i.e. in the following 90 or 160 days, rather than over a shorter horizon such as one month (20 days). Directors are likely to trade based on longer term developments not captured by disclosure of specific events.

Directors' trades do contain information regarding the future predictability of the firms' share price. Outsiders recognise this and react to the disclosure of directors' sales, however the price is slow to adjust; abnormal returns exist well after the disclosure of the trade. Outsiders are able to profitably mimic the trading of directors' sales, and purchases made by directors of small companies. Even if outsiders are unable to closely imitate the trading of directors, they may be able to use this information as an indication of when not to buy or sell shares.

The finding that both directors beat the market and that outsiders can develop implemental trading strategies based on this information contradicts much of traditional finance and the Efficient Market Hypothesis. Our results not only contradict the strong form of market efficiency but also the semi-strong form for most trades conducted by directors. Directors and investors are loss averse and quick to 
react to potential losses, yet slow to incorporate and trade based on equivalent potential gains. We cannot discredit the Efficient Market Hypothesis completely. It is evident that outsiders do react to some information contained in directors' trades, especially for sales. Because of the difficulty involved in interpreting the disclosure made by a director however, investors are unable to discern the supposed information contained in directors' trades. Thus, the information is not immediately fully incorporated into prices, but is eventually.

\subsection{Avenues for Further Research}

The most pressing need is to extend the sample size and the sample period. Another avenue would be to incorporate transaction costs and industry affects in the calculation of abnormal return and volume. Thin trading is a problem affecting our sample, as is the survivorship criterion, which both introduces biases into the study. Also, because the study introduces an intensive trading criterion, it may be difficult for outsiders to mimic trading because an intensive trading firm can only be identified after a number of trades have already taken place. Additionally, because the data are purged and only one trade is selected to represent the trades of that firm, our study does not show the profitability of all trades, but is merely just a small proportion of total trades. Additionally, in calculating the profitability of directors' trades, we are not sure about the actual holding periods of directors; our study shows possible abnormal returns, rather than actual returns.

Like all other insider trading studies, our research does not provide any examination of instances of non-trading due to the possession of inside information. Nor does it provide evidence pertaining to trades by directors or other individuals privy to inside information, but which were not disclosed to the ASX. ${ }^{6}$ Another extension would be to examine trading by directors in other markets. Considering that directors do earn abnormal returns and are likely to conduct in insider trading, they are likely to trade securities in other markets that are not so heavily scrutinised or regulated.

${ }^{6}$ Our study does include trades by immediate family members of directors, which were disclosed to the ASX. 
There is also a pressing need to further examine the pattern of volume surrounding the directors' trades. Our study touched on volume, however the results are confounding in that volume begins to increase before the director has actually traded. In order to determine the actual reason for the increase before and after the trade, it would be beneficial to conduct further empirical analysis taking into account intra-day data, the effect of the director's own trading volume as a proportion of abnormal volume and the occurrence of company announcements. 


\section{References}

Agarwal, M. and H. Singh (2006). "Merger Announcements and Insider Trading Activity in India: An Empirical Investigation." Investment Management and Financial Innovations 3: 140-54.

Aitken, M. and R. Czernkowski (1992). "Information Leakage Prior to Takeover Announcements: The Effect of Media Reports." Accounting and Business Research 23(89): 3-20.

Baesel, J. and G. Stein (1979). "The Value of Information: Inferences from the Profitability of Insider Trading." Journal of Financial and Quantitative Analysis 14: 553-71.

Bainbridge, S. (1998). "Insider Trading: An Overview." Working Paper, UCLA School of Law.

Bettis, C., D. Vickrey and D.W. Vickery. (1997). "Mimickers of Corporate Insiders who make large volume trades." Financial Analysts Journal 1997(53): 57-66.

Bhattacharya, U. and H. Daouk (2002). "The World Price of Insider Trading." The Journal of Finance 57(1): 75-108.

Brown, P. and M. Foo (1997). "Insider Trading in Australia: Evidence from Directors' Trades." Working Paper, Department of Accounting and Finance, University of Western Australia.

Carlton, D. and D. Fischel (1983). "The Regulation of Insider Trading." Stanford Law Review 35: 85795.

Cornell, B. and E. R. Sirri (1992). "The Reaction of Investors and Stock Prices to Insider Trading." Journal of Finance 47(3): 1031-59.

Corporations and Markets Advisory Committee (2003). Insider Trading Report. Sydney.

Daniel, K., D. Hirshleifer and S.H. Teoh (2002). "Investor Psychology in Capital Markets: Evidence and Policy Implications." Journal of Monetary Economics 49: 139-209.

Dimson, E. and P. Marsh (1986). "Event Study Methodologies and the Size Effect: The Case of UK Press Recommendations." Journal of Financial Economics 17: 113-42.

Elias, D. (2005). Insider trading by any other name. Sydney Morning Herald. Sydney.

Elliot, J., D. Morse and Richardson G (1984). "The Association between Insider Trading and Information Announcements." Rand Journal of Economics 15: 521-36.

Fama, E. F. (1998). "Market Efficiency, Long-term Returns, and Behavioural Finance." Journal of Financial Economics 49: 283-306.

Finnerty, J. (1976). "Insiders and Market Efficiency." Journal of Finance 31: 1141-8.

Friedman, M. (2003). Friedman: Trust markets to weed out corporate wrongdoers, CNBC. 2006: Transcript of an interview with Michelle Caruso-Cabrera on CNBC's Power Lunch.

Gao, Y. N. and D. Oler (2004). Trading in Target Stocks before Takeover Announcements.

Gettler, L. (2005). Directors breaking share trading rules. Sydney Morning Herald, November, 12.

Givoly, D. and D. Palmon (1985). "Insider Trading and the Exploitation of Inside Information: Some Empirical Evidence." Journal of Business 58(1): 69-87.

Hillier, D. and A. P. Marshall (2002). "The Market Evaluation of Information in Directors' Trades." Journal of Business Finance and Accounting 29(1) \& (2): 77-110. 
Hodgson, A and B.V. Parag (2006). "Information trading by corporate insiders based on accounting accruals: forecasting economic performance." Accounting and Finance (46)5: 819-842.

Jaffe, J. F. (1976). "Special Information and Insider Trading." Journal of Business 47(3): 410-28.

Jarrell, G. and A. Poulsen (1989). "Stock Trading before the Announcement of Tender Offers: Insider Trading or Market Anticipation?" Journal of Law, Economics \& Organization 5(2): 225-48.

Jeng, L., A. Metrick , and R. Zeckhauser (2003). "Estimating the Returns to Insider Trading: A Performance-Evaluation Perspective." The Review of Economics and Statistics 85(2): 453-71.

Jensen, M. (1978). "Some Anomalous Evidence Regarding Market Efficiency." Journal of Financial Economics 6(2/3): 95-101.

John, K. and L. Lang (1991). "Insider Trading around Dividend Announcements: Theory and Evidence." Journal of Finance 45(4): 1273-84.

Kahneman, D. and A. Tversky (1979). "Prospect Theory: An Analysis of Decision under Risk." Econometrica 47(2): 263-92.

Kahneman, D. and A. Tversky (1991). "Loss Aversion in Riskless Choice: A Reference-Dependent Model." The Quarterly Journal of Economics 106(4): 1039-61.

Keown, A. and J. Pinkerton (1981). "Merger Announcements and Insider Trading Activity: An Empirical Investigation." Journal of Finance 36: 855-69.

Lakonishok, J. and I. Lee (2001). "Are Insider Trades Informative?" The Review of Financial Studies 14(1): 79-111.

Lee, D.S, W. H Mikkelson and M.M. Partch (1992). "Managers' Trading Around Stock Repurchases." Journal of Finance 37(5): 1947-61.

Lin, J. and J. Howe (1990). "Insider Trading in the OTC Market." Journal of Finance 45(4): 1273-84.

Lorie, J. H. and V. Niederhoffer (1968). "Predictive and Statistical Properties of Insider Trading." Journal of Law and Economics 11(1): 35-53.

Lyon, J. D., B.M. Barber and C. L. Tsai (1999). "Improved Methods for Tests of Long-run Abnormal Stock Returns." Journal of Finance 54(1): 165-201.

Manne, H. (1966). Insider Trading and the Stock Market. New York, The Free Press.

Meulbroek, L. (1992). "An Empirical Analysis of Illegal Insider Trading." Journal of Finance 47(5): 1661-99.

Mitchell, J. and I. Watson (2004). An Investigation of Insider Trading around Australian Share Buybacks. European Financial Management Association Annual Conference, Basel, http://www.wwz.unibas.ch/cofi/efma/apl.htm\#M.

Novemsky, N. and D. Kahneman (2005). "The Boundaries of Loss Aversion." Journal of Marketing Research 42(2): 119-28.

Nunn, K., G. Madden, et al. (1983). "Are Some Insiders More 'Inside' than Others?" Journal of Portfolio Management 9: 18-22.

Park, S., H.J. Jang and M.P. Loeb (1995). "Insider Trading Activity Surrounding Annual Earnings Announcements." Journal of Business Finance and Accounting 22(4): 587-614.

Rozeff, M. and M. Zaman (1988). "Market Efficiency and Insider Trading: New Evidence." Journal of Business 61(1): 25-44. 
Seyhun, N. (1986). "Insider Profits, Costs of Trading and Market Efficiency." Journal of Financial Economics 16: 189-212.

Seyhun, N. (1992). "Why Does Aggregate Insider Trading Predict Future Stock Returns." The Quarterly Journal of Economics 107(4): 1303-31.

Sivakumar, K. and G. Waymire (1994). "Insider Trading Following Material News Events: Evidence from Earnings." Financial Management 24: 23-32.

Tomasic, R. (1991). Casino Capitalism?: Insider Trading in Australia, Australian Institute of Criminology.

Watson, I. and A. Young (1998). "A Preliminary Examination of Insider Trading Around Takeover Announcements in Australia." Working Paper, Department of Accounting and Finance, University of Western Australia.

(1991). Corporations Legislation Amendment Bill Explanatory Memorandum. 


\section{Appendix}

TABLE 1. Descriptive Statistics: Directors' trades of intensive trading firms Period: July - December 2005

\begin{tabular}{cc|cc|cc|cr}
\cline { 2 - 6 } \\
\hline \multicolumn{2}{c|}{ All trades } & \multicolumn{2}{c|}{ Sreakdown by Company Size* } \\
Buy & Sell & Buy & Sell & Buy & \multicolumn{3}{c}{ Large } \\
\hline
\end{tabular}

Panel A. Total trades

Number of trades

472

Number of firms

63

318

318
55

\begin{tabular}{c|c}
\hline 22 & 98 \\
4 & 19
\end{tabular}

98
19

\begin{tabular}{c|cc}
\hline 28 & 56 & 13 \\
5 & 8 & 3 \\
\hline
\end{tabular}

\section{Panel B. Directors' trades by trade size}

Mean**

Minimum 41,801

Maximum

191,582

$6,149,327$

$10,000,000$

\begin{tabular}{|cc|cc|cc}
\hline 49,369 & 216,058 & 36,659 & 127,341 & 1,876 & 46,693 \\
50 & 4,000 & 275 & 730 & 71 & 1,000 \\
$3,746,734$ & $6,099,391$ & $2,370,000$ & $10,000,000$ & $6,149,327$ & $5,781,000$ \\
\hline
\end{tabular}

\section{Panel C. Directors' trades by value (\$)***}

\section{Mean**}

Minimum

$\begin{array}{cc}150,059 & 951,965 \\ 38 & 1,480\end{array}$

Maximum $16,500,000$

$27,600,000$

\begin{tabular}{|cc|cc|cc|}
\hline 53,845 & 77,261 & 50,764 & 927,415 & 20,406 & $1,697,506$ \\
38 & 1,480 & 1,400 & 2,000 & 2,304 & 10,060 \\
$16,500,000$ & 682,400 & $5,192,000$ & $27,600,000$ & $12,544,627$ & $21,794,370$ \\
\hline
\end{tabular}

* Large companies are defined as Top 150 companies according to market capitalisation as of 28 September 2006 . Medium companies are Top 500 companies excluding those in the Top 150; and Small companies are those outside the Top 500.

** Outliers were removed from the sample for the purpose of calculating the average trade.

*** Number of shares traded multiplied by closing daily share price 
Table 2. Frequency Distribution for Number of Shares Traded by Directors

\begin{tabular}{ccccccccc} 
& \multicolumn{7}{c}{} & \multicolumn{5}{c}{ Breakdown by Company Size } \\
\cline { 2 - 9 } All trades & \multicolumn{3}{c}{ Small } & Medium & \multicolumn{2}{c}{ Large } \\
No. of shares & Buy & Sell & Buy & Sell & Buy & Sell & Buy & Sell \\
\hline$\leq 500$ & 8 & 0 & 1 & 0 & 1 & 0 & 6 & 0 \\
$501-5,000$ & 95 & 6 & 39 & 1 & 21 & 1 & 35 & 4 \\
$5,001-10,000$ & 45 & 6 & 28 & 1 & 15 & 4 & 2 & 1 \\
$10,001-25,000$ & 71 & 6 & 54 & 3 & 17 & 3 & 0 & 0 \\
$25,001-50,000$ & 77 & 6 & 62 & 1 & 11 & 4 & 4 & 1 \\
$50,001-100,000$ & 69 & 8 & 54 & 3 & 13 & 3 & 2 & 2 \\
$100,001-500,000$ & 72 & 17 & 58 & 8 & 10 & 7 & 4 & 2 \\
$500,001-1,000,000$ & 19 & 4 & 13 & 2 & 5 & 1 & 1 & 1 \\
$1,000,001-5,000,000$ & 15 & 7 & 9 & 2 & 5 & 4 & 1 & 1 \\
$>5,000,000$ & 1 & 3 & 0 & 1 & 0 & 1 & 1 & 1 \\
Total & & & & & & & & \\
\end{tabular}

